\title{
Life History Parameters of the Tomato Red Spider Mite Tetranychus evansi (Acari:Tetranychidae), Collected in Syria, on Two Solanaceous Plants
}

\author{
Ghais Zriki; Ibrahim Saker and Angham Bouou \\ Department of Plant Protection, Faculty of Agriculture, Tishreen University \\ Lattakia, Syria. E-mail: ghaiszriki@hotmail.com
}

\begin{abstract}
The effect of the two host plants Solanum lycopersicum and Solanum nigrum belonging to the family Solanaceae on biological (survival and duration of developmental stages, fecundity and longevity of females and sex ratio) and demographic parameters $(R 0, G, r \mathrm{~m}$ and $\lambda)$ of Tetranychus evansi was studied in the laboratory under controlled conditions: $25^{\circ} \mathrm{C} \pm 0.5^{\circ} \mathrm{C}, 75 \pm 10 \% \mathrm{RH}$ and $16 \mathrm{~L}: 8 \mathrm{D}$. The rise of Intrinsic rate of increase $\left(r_{m}=0.242\right.$ day $\left.^{-1}\right)$ of the mite population, and time needed to duplicate population numbers $(D \mathrm{t}=2.11$ day) on $S$. nigrum compared to $S$. lycopersicum $\left(r_{m}=0.215\right.$ day $^{-1}, D t=20.23$ day) refers to $S$. nigrum as a favorable host to $T$. evansi.
\end{abstract}

Key Words: Tetranychidae, Tetranychus evansi, Biological Aspects, Demographic Parameters, Solanum lycopersicum.

\section{INTRODUCTION}

Tetranychus evansi Baker \& Pritchard 1960, is a well-known crop pest, In the last two decades this subtropical tomato red spider mite, expanded its geographical distribution and emerged as a major invasive agricultural pest (Navajas et al., 2012). Several researchers consider it to be native to South America (Gutierrez \& Etienne, 1986). It was recorded on tomato, egg plant, potato, peanut and various other plants in Mauritius, Texas and Brazil (Silva, 1954; Moutia, 1958; Baker \& Pritchard, 1960). Therefore, it spread rapidly throughout the world and becomes an important pest on solanaceous plants. Currently, this pest is well established in the Mediterranean, and considered as a new threat to both outdoor and protected cultivations of solanaceous crops in Africa and the Mediterranean basin, with invasions characterized by a high reproductive output and an ability to withstand a wide range of temperatures (Boubou et al., 2009, 2011). According to the model desined by Migeon (2005) about its distribution in the world, the whole Mediterranean region, the main area where tomato is grown in open fields; and where this species represents a threat, has the potential to be extensively colonized by the mite.

Until now, few studies have been conducted on the biology of T.evansi. Gotoh, et al (2009); Qureshi et al. (1969) assessed the egg-to-adult developmental time and fecundity of a Californian $T$. evansi strain on nightshade (Solanum douglasii) leaves, and de Moraes and McMurtry (1987) examined the lower thermal threshold and lifehistory parameters of the Californian $T$. evansi strain on S. douglasii. Bonato (1999) reported the lower thermal threshold and life-history parameters of F. evansi from Congo on tomato leaves. Also Gotoh et al., (2010) used a temperature range from 15 to 35 $\mathrm{C}^{\circ}$ to compare seven strains of $T$. evansi originating from different parts of the world, including South America and newly invaded continents,. Hence, information on the life-history of T. evansi itself is scarce and fragmentary.

It is becoming increasingly evident that the establishment of effective control strategies requires a detailed knowledge of the biology, genetic structure and geographical variability, of a given species (Roderick and Navajas, 2003).

The objective of the present study was to estimate the severity of $T$. evansi by comparing the effect of its main two hosts (Solanum nigrum and Solanum lycopersicum) on development and reproduction of this strain, we have detected in Syria.

\section{MATERIALS AND METHODS}

\section{Mite rearing and host plant production}

Experiments were carried out using descendants of several females taken from a field located in Lattakia (Syria), in which neither acaricides nor insecticides had been applied ( $T$. evansi used in this experements was found on nightshade $S$. nigrum at $1 / 11 / 2103$ ). Mites were maintained (25 days before starting the experiments ) on down-side-up leaf of nightshade and tomato ( $S$. nigrum and $S$. lycopersicum respectively) placed on watersaturated cotton mats in glass dishes $(200 \mathrm{~mm}$ diameter, $20 \mathrm{~mm}$ depth) and kept at $25 \pm 1{ }^{\circ} \mathrm{C}$, $60-70 \%$ relative humidity and $16 \mathrm{~L}: 8 \mathrm{D}$ photoperiod 
. Nightshade and tomato plants were cultivated in pots and grown in greenhouse under $20 \pm 5{ }^{\circ} \mathrm{C}$ and $75 \pm 10 \% \mathrm{RH})$. Leaf discs were taken from leaves of both plants of the same variety grown under the above-mentioned conditions.

\section{Experimental conditions}

Studies were performed at constant temperatures, $25 \pm 0.5^{\circ} \mathrm{C}$. Leaf discs $\left(4 \mathrm{~cm}^{2}\right)$ were maintained on water-soaked cotton and replaced when needed, every 3-5 days. All experiments were carried out in an incubator at RH $75 \pm 10 \%$. Light (16L: 18D) was provided by fluorescent tubes.

\section{Immatures development and reproduction}

Nine to ten females were placed on each leaf disc (ca. $4 \mathrm{~cm}^{2}$ ) and after 2 hours, the females and excess eggs were killed to obtain one egg per disc. The eggs were monitored to determine the development and survival rate of immature stages: larva, protochrysalis, protonymph, deutochrysalis, deutonymph and tritochrysalis, respectively, 1, q1, $\mathrm{p}, \mathrm{q} 2, \mathrm{~d}$ and $\mathrm{q} 3$. Each individual was examined two-three times a day (at 8:30 a.m., 2:30 p.m. and at 5 p.m.) and the transition from one stage to another was noted.

When a female was in a tritochrysalis stage, two adult males were introduced to the leaf disc for mating. The new adult females were observed at a 24-hr interval to assess the date of first oviposition. The number of eggs laid by each female was recorded daily throughout its life. The female was transferred to a new leaf disc when neaded, and discs with eggs were maintained under the same experimental conditions as for females. The sex ratio was determined on the basis of a count of adults originating from those eggs during the first five days from the oviposition period. Sex ratio was defined as the proportion of females in the progeny. Non-mated females, i.e. producing only males, were not taken into account.

Statistical analysis and Demographic parameters

Data on developmental time, duration of female reproductive periods and fecundity were analyzed using one-way ANOVA). These statistical analyses were performed using PASW ver. 20. Daily age-specific survival (lx) and fecundity rates $(\mathrm{mx})$ were used to generate life-tables. The net reproductive rate $\left(R_{0}\right), \quad R_{0}=\Sigma l_{x} m_{x}$. the mean generation time (T), $T=\sum x l_{x} m_{x} / R_{\theta}$, the intrinsic rate of natural increase $\left(r_{\mathrm{m}}\right), r_{\mathrm{m}}=\ln R_{o} / T$; the doubling time $(D \mathrm{t})$ in days $D \mathrm{t}=\ln 2 / r_{m}$ and the finite rate of increase $(\lambda)$ was given by $\lambda=\mathrm{e}^{\mathrm{rm}}$. All these parmeters were calculated using the method recommended by Birch (1948) and Bank et al. (2006).

\section{RESULTS AND DISCUSSION}

\section{Immatures development and survival rate}

The egg-to-adult developmental duration of mite of both sexes was significantly different among the two host plants, according to analysis of variance (ANOVA) $(\alpha=0.05 ; F=585.5 ; \mathrm{df}=109$ and $p=$ 0.0004). According to the present T.evansi developed faster on S.nigrum; developmental time was 9.2 days on S.nigrum and 9.6 days on S.lycopersicum.

Table 1 shows the duration of each immature stage of $T$. evansi. Total duration of the immature stages of males was slightly shorter than that of females (Table 1). The egg stage was the longest, lasting from 3.7 days on $S$. nigrum to 4.2 on $S$. lycopersicum. The durations of other stages were similar to one another on each of the two hosts, the active larval, protonymph and quiescent deutonymphal stages were slightly longer than other stages. Some immature stages developmental durations displayed significant differences among hosts.

\section{Female development}

No significant differences were found in preoviposition, oviposition period, post-oviposition period and adult longevity between the two hosts. The statistical analyses revealed differences between treatments for the first oviposition date $(\alpha=0.05, F$ $=29.929$, df $=49$ and $p<0.0001)$, total eggs per female $(\alpha=0.05, F=35.228$, df $=49$ and $p<$ $0.0001)$ and daily egg production (eggs/female/day) $(\alpha=0.05, F=22.71, \mathrm{df}=53$ and $p<0.0001)$. The total number of eggs laid per female on S.nigrum (210.9) was higer than on S. lycopersicum (124.8) (Table 2). Daily average of ovipostion followed similar pattern where the maximum was 17.41 eggs per female on S.nigrum and 9.16 eggs per female on S. lycopersicum, Maximum longevity of 44.9 days was recorded on $S$. lycopersicum and 48.1 on $S$. nigrum (Figs. 1, 2 respectively and Table 2).

\section{Sex ratio}

The averge sex ratio over the first 5 days of the oviposition period revealed no significant difference between tratments were found. Sex ratio was higher on S.nigrum but no significant difference was found. The number of eggs laid and the survival ratio during the first 5 days was significantly different $(\alpha$ $=0.05, F=5.844$, df $=33$ and $p=0.022),(\alpha=0.05$, $F=22.998, \mathrm{df}=33$ and $p<0.0001)$ (Table 3).

\section{Demographic parameters}

The net reproductive rate $\left(R_{0}\right)$ and the intrinsic rate of natural increase $\left(r_{m}\right)$ were higher on $S$. nigrum than on $S$. lycopersicum. Mean generation 
Table (1): Mean ( \pm SD) duration in days of the egg (e), larva (1), protonymph (p), deutonymph (d) and quiescent stages (q1, q2 and q3) of T. evansi on nightshade and tomato under constant temperature :25 \pm $0.5^{\circ} \mathrm{C}, 75 \pm 10 \% \mathrm{RH}$ and $16 \mathrm{~L}: 8 \mathrm{D}$ photoperiod

\begin{tabular}{|c|c|c|c|c|c|c|}
\hline \multirow{3}{*}{ Stage } & & & host & & & \\
\hline & \multicolumn{2}{|c|}{ Male+female } & \multicolumn{2}{|c|}{ female } & \multicolumn{2}{|l|}{ male } \\
\hline & S.lycopersicum & S.nigrum & S.lycopersicum & S.nigrum & S.lycopersicum & S.nigrum \\
\hline $\mathrm{e}$ & $4.0(0.2) \mathrm{a}$ & $3.9(0.2) \mathrm{a}$ & $4.1(0.2) \mathrm{a}$ & $3.9(0.2) \mathrm{a}$ & $3.9(0.2) \mathrm{a}$ & $4.0(0.2) \mathrm{a}$ \\
\hline 1 & $0.9(0.1) \mathrm{a}$ & $0.9(0.1) \mathrm{a}$ & $0.9(0.1) \mathrm{a}$ & $0.9(0.1) \mathrm{a}$ & $0.8(0.1) \mathrm{a}$ & $0.9(0.1) a$ \\
\hline $\mathrm{q} 1$ & $0.9(0.1) \mathrm{b}$ & $0.8(0.1) \mathrm{a}$ & $0.9(0.1) \mathrm{b}$ & $0.8(0.1) \mathrm{a}$ & $0.9(0.1) \mathrm{a}$ & $0.8(0.1) \mathrm{a}$ \\
\hline $\mathrm{P}$ & $0.9(0.1) \mathrm{b}$ & $0.8(0.1) \mathrm{a}$ & $1(0.1) \mathrm{b}$ & $0.8(0.1) \mathrm{a}$ & $0.8(0.1) \mathrm{a}$ & $0.8(0.1) \mathrm{a}$ \\
\hline$q 2$ & $0.9(0.1) \mathrm{a}$ & $0.8(0.1) \mathrm{a}$ & $0.9(0.1) \mathrm{b}$ & $0.8(0.1) \mathrm{a}$ & $0.8(0.1) \mathrm{a}$ & $0.8(0.1) \mathrm{a}$ \\
\hline $\mathrm{d}$ & $1(0.1) \mathrm{a}$ & $1(0.1) \mathrm{a}$ & $1(0.1) \mathrm{a}$ & $1(0.1) \mathrm{a}$ & $1(0.1) \mathrm{a}$ & $0.9(0.1) \mathrm{a}$ \\
\hline $\mathrm{q} 3$ & $1.0(0.2) \mathrm{b}$ & $0.9(0.1) \mathrm{a}$ & $1.1(0.2) \mathrm{b}$ & $0.9(0.1) \mathrm{a}$ & $0.9(0.1) \mathrm{a}$ & $0.8(0.1) \mathrm{a}$ \\
\hline Egg- adult & $9.6(0.5) \mathrm{b}$ & $9.2(0.5) \mathrm{a}$ & $9.8(0.8) \mathrm{b}$ & $9.2(0.5) \mathrm{a}$ & $9.1(0.3) \mathrm{a}$ & $9.1(0.7) \mathrm{a}$ \\
\hline $\mathrm{N}$ & 58 & 52 & 41 & 39 & 17 & 13 \\
\hline
\end{tabular}

$\mathrm{N}=$ Number of females tested

Durations followed by the same letters within a row are not significantly different. (ANOVA, $a=0.05$ ).

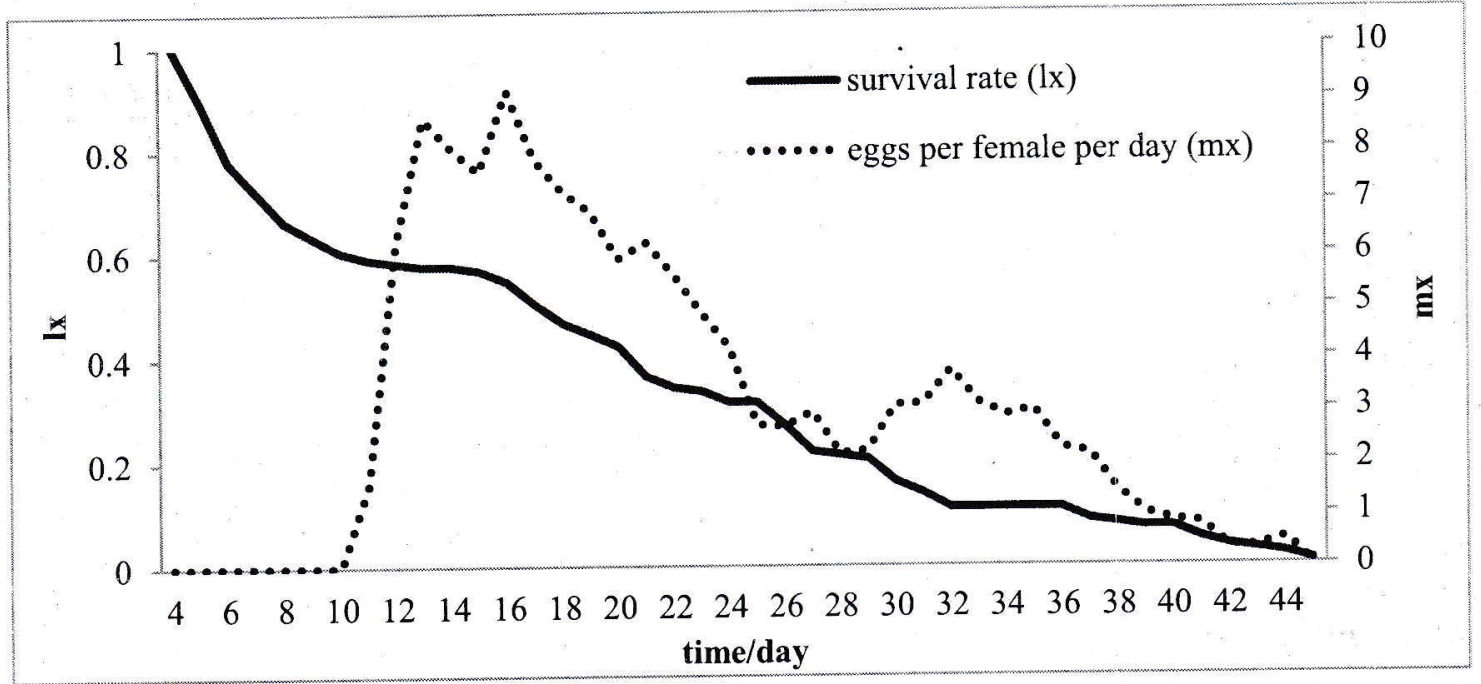

Fig. (1): Age-specific survival rate (lx) and daily fecundity rate $(\mathrm{mx})$ of T.evansi on S.lycopersicum leaf disc at $25 \pm 0.2^{\circ} \mathrm{C}$.

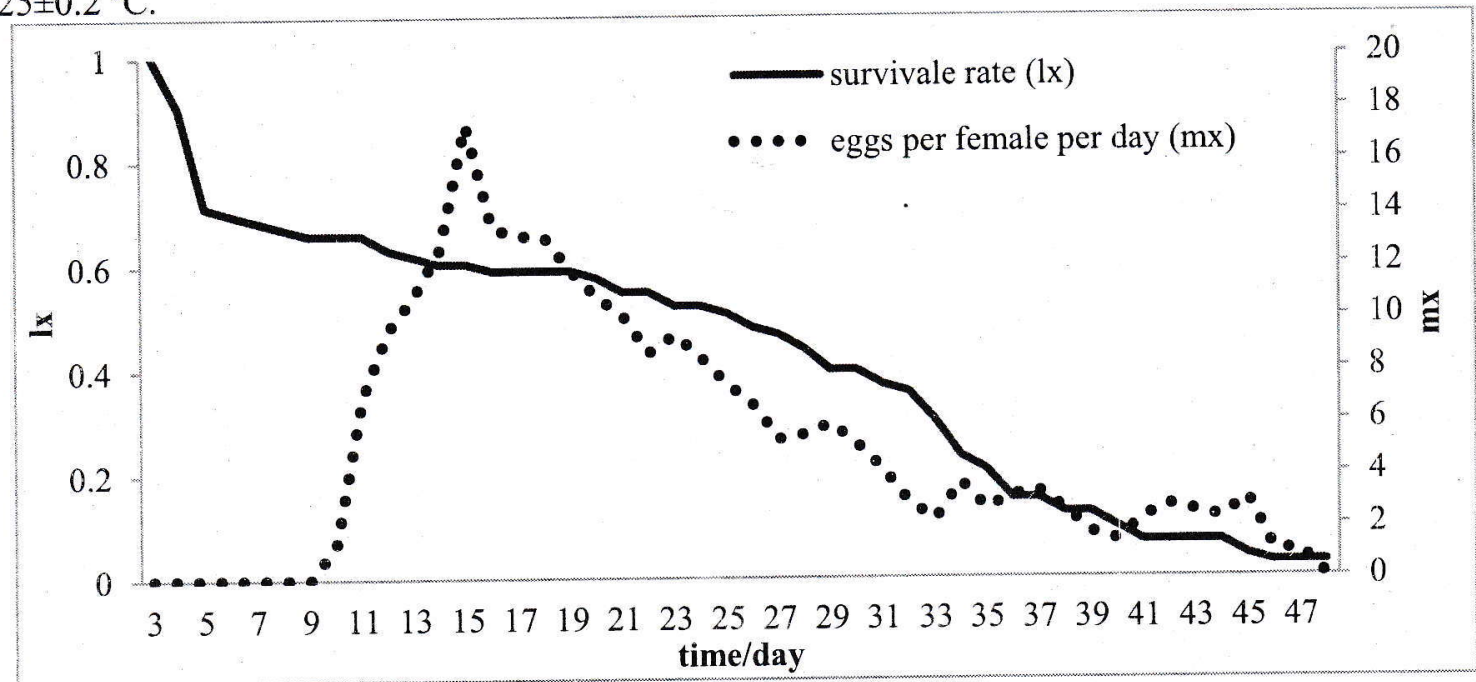

Fig. (2): Age-specific survival rate (lx) and daily fecundity rate (mx) of T.evansi on S.nigrum leaf disc at $25 \pm 0.2^{\circ} \mathrm{C}$. 
Table (2): Mean ( $(\mathrm{SD})$ duration in days of preoviposition, oviposition and postoviposition periods, longevity and various reproductive parameters: ovipositional rates and peak oviposition rate of $T$. evansi

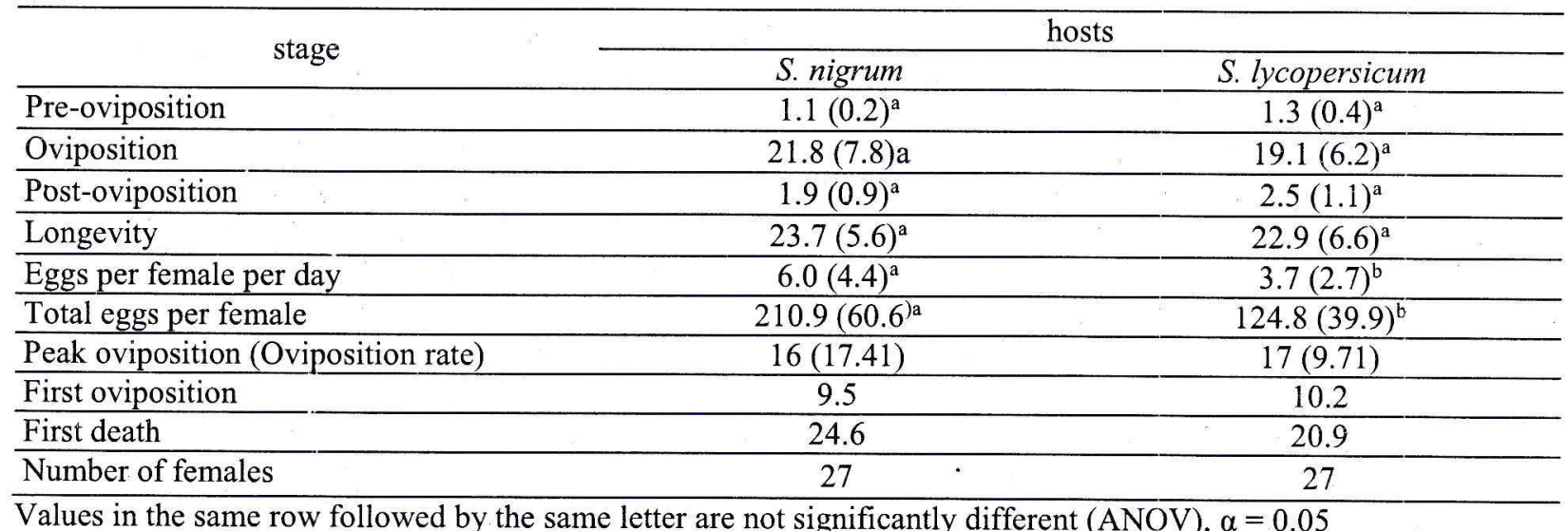

Values in the same row followed by the same letter are not significantly different (ANOV), $\alpha=0.05$

Table (3): Number of eggs laid during the first 5 days of the oviposition period, hatchability of eggs, survival rate of immature stages and the proportion of females reaching adulthood (mean $\pm \mathrm{S}$. D.) on S.nigrum and S.lycopersicum at $25^{\circ} \mathrm{C}, 75 \% \mathrm{RH}$ and under $16 \mathrm{~L}: 8 \mathrm{D}$ photoperiod

\begin{tabular}{lccccc}
\hline Host & N & No. of eggs laid & \% Hatch & \% Survival & $\%$ Female \\
\hline S.lycopersicum & 17 & $43.4(9.4) \mathrm{a}$ & $99.2(1.3) \mathrm{a}$ & $89.4(5.7) \mathrm{a}$ & $88.6(4.4)$ \\
\hline S. nigrum & 17 & $52.6(12.6) \mathrm{b}$ & $99.2(1.1) \mathrm{a}$ & $96.7(2.6) \mathrm{b}$ & $90.3(4.5)$ \\
\hline $\mathrm{N}=$ Number of females tested & &
\end{tabular}

$\mathrm{N}=$ Number of females tested

Durations followed by the same letters within a row are not significantly different.

Table (4): Effect of host plants on age-specific fecundity schedules of T. evansi at constant conditions $25^{\circ} \mathrm{C}$, $75 \% \mathrm{RH}$ and under $16 \mathrm{~L}: 8 \mathrm{D}$ photoperiod

\begin{tabular}{lcccccc}
\hline \multirow{2}{*}{ hosts } & \multicolumn{7}{c}{ Demographic parameters } \\
\cline { 2 - 7 } & $R_{0}$ & $\mathrm{G}$ & $r_{m}$ & $\lambda$ & $\mathrm{Dt}$ & $\mathrm{GRR}$ \\
\hline S.nigrum & 115.43 & 19.65 & 0.2417 & 1.27 & 2.113 & 236.89 \\
\hline S.lycopersicum & 49.71 & 18.20 & 0.2147 & 1.24 & 2.232 & 116.32 \\
\hline
\end{tabular}

time $(T)$, finite rate of increase $(\lambda)$ and doubling time $(D \mathrm{t})$ were also different between the two tested hosts (Table 4).

Development from egg to adult at $25 \mathrm{C}^{\circ}$ was faster for the local $T$. evansi strain (9.2 Day) than in the Californian strain used by de Moraes and McMurtry (1987) (13.6 days), and in the seven strains used by Gotoh (2010) (9.7 - 10.7 days) despite the fact that both studies used nightshades as food source. This difference may be due to the age of the eggs used in Gotoh study (0-24 h) and to differences in the observation intervals: in the Gotoh study being every $24 \mathrm{~h}$ versus 3 times/ day here when tomato used as a food source. The developmental time was also less in the present study than in the Congo strain used by Bonato (1999) and examined on the same host plants.

Several researchers have studied the reproductive traits of $T$. evansi, and different results were obtained. For the Californian strain on nightshade, de Moraes and McMurtry (1987) reported an oviposition period of 29.0 days at $25 \mathrm{C}^{\circ}$ versus 21.8 days in the present study, thus, the Californian strain had a longer oviposition period than that strain in the present study. For the seven strains in Gotoh study, the oviposition period which he reported was 17.323.1 days at $25 \mathrm{C}^{\circ}$, and the same period for the local strain fell into this range.

The total fecundity of the Californian strain (243 eggs) was much higer than the strain used here (210.9) and the seven strains used in Gotoh study (137-173.5). This may be due to the long oviposition period of the Californian strain.

- When tomato was used as a source of food, the present study reported an oviposition period much longer than the Congo strain. The total fecundity followed similar pattern where it was higher in the present study (124.8) than it in the former study(111.1 egg/female). This differences may be resulted from the long oviposition period of the local 
syudy and from the difference in the experimental condition of photo period (12:12 in the former study and 16L:8D in the present study), despite that Congo strain examained at $26 \mathrm{C}^{\circ}$.

Generally, life-table parameters from different studies are difficult to compare, as differences can be due to the organisms as well as the experimental methodology. For instance details of rearing method, environmental conditions other than temperature, and inclusion or exclusion in life-history calculations of aspects such as survival of eggs to adult stage and sex ratio were studded (Bonato, 1999 and Gotoh, 2010). Nevertheless, Sabelis (1985a, 1991), in an extensive review of life-history parameters of tetranychid mites, found the rm-values for Tetranychus mites to range from 0.200 to 0.336 day $^{-1}$ at ca. $25^{\circ} \mathrm{C}$. The rm-values of $T$. evansi fell within this range. At $25-26^{\circ} \mathrm{C}$, the rm-values of various $T$. evansi strains were 0.200 (de Moraes and McMurtry 1987), 0.243 (Bonato, 1999), 0.265-0.277 day $^{-1}$ (Gotoh, 2010), 0.242 day $^{-1}$ on nightshade and 0.215 day $^{-1}$ on tomato in the present study.

These differences in the rm-values may be explained by the lower sex ratio $(42.9 \%)$ for the Californian strain despite the comparable values of peak oviposition on day 19(de Moraes and McMurtry, 1987), when compared with those of the present study. Contradictory, despite the higher peak oviposition (17.41 eggs on day 16) for the local strain reared on $S$. nigrum, the $r_{m}$ value here was lower than the seven strains in Gotoh study. This may be due to the reduction of survival ratio $1 \mathrm{x}$ in the present study when compared with those of Gotoh study.

- The $r_{m}$ value for the local strain reared on tomato was also lower than that of the Congo strain, this may be explained by the high daily oviposition rate 8.2 (egg/female/day) (Bonato, 1999) versus 3.7 (egg/female/day) in the present study.

The rise of Intrinsic rate of increase $\left(r_{m}\right)$ of the mite population, and time needed to duplicate population numbers $(D t)$ on $S$. nigrum compared to $S$. lycopersicum refer to $S$. nigrum as a favorable host to $T$. evansi which matches to previous results. This also refers to the examined strain as a relatively less severity one according to not showing same increasing ability once moved from one host (S. nigrum) to another (S. lycopersicum). Taking in consideration the fact that this strain was raised on ( $S$. lycopersicum) a month before starting experiment.

According to genetic researches that mention two Bio-types differ in invasive potential, this difference comes back to other differences in biological characteristics and correlation to botanic host.

The bio-type having a higher invasive potential usually shows up as infection with high mite densities and wide spread, it was mostly found on varied plants of Solanaceae at infected areas like $S$. lycopersicum and $S$. melongena at greenhouses, Capsicum annuum and $S$. tuberosum in Algeria. On the other hand, the second bio-type is less truculent, found basically on $S$. nigrum and not showing any intensive infection (Boubou et al., 2011).

Accordingly to this, the local strain found in Latakia area belongs to the bio-type with less invasive potential, that is related to retraction in increasing ability once moved from S.nigrum and raised on S. lycopersicum. But These evidences don't weighs much taking many reasons in consideration. First, we didn't perform a comprehensive survey to plants surrounding S.nigrum and S. lycopersicum infested with $T$. evansi. Second, reduction in the mite age-specific fecundity schedules in researches used $S$. lycopersicum as a host compared to using $S$. nigrum, (Bonato, 1999). In addition, genetic analyses researches mentions that biotype with low invasive potential exists in South America and limited areas in France \& Catalonian-Spain, while the other bio-type invades the whole Mediterranean basin, eastern Asia countries, and it's the one registered in Palestine. (Boubou, et al., 2009, Boubou et al., 2011).Suppose that the strain exists in research area belongs to the bio typ with low invasive potential, that doesn't really deny the existence of the second bio-type, and refers at the same time that the tow biotypes are exsesting to gether here.

In case the highly invasive potential doesn't exist at the area that suggests intensification of agricultural quarantine procedures to prevent it from invading the area.

Generally, this point needs to perform more expanded researches in terms of widening research area and increasing the number of collected samples, as well as the necessity of starting genetic analyses researches of $T$. evansi populations exists in Syria. Because such steps considered essential and fundamental to formation strategies to resist and controle invading pest which is considered new to Solanaceae crops causing serious damages in the areas recorded at.(Boubou, et al., 2011, Rodrick \& Navajas, 2003). 


\section{REFERENCES}

Baker, E. W. and Pritchard, A. E. 1960. The tetranychoid mites of Africa. Hilgardia 29: 119 pp.

Banks, H. T.; Banks, J. E.; Dick, L. K. and Stark, J. D. 2006. Estimation of dynamic rate parameters in insect populations undergoing sublethal exposure to pesticides. Center for Research in Scientific Computation, North Carolina State University, Raleigh, North Carolina, $44 \mathrm{pp}$.

Birch, L. C. 1948. The intrinsic rate of increase of an insect population. J. Anim. Ecol, 17:15-26.

Bonato, O. 1999. The effect of temperature on life history parameters of Tetranychus evansi (Acari: Tetranychidae). Exp. Appl. Acarol. 23:11-19

Boubou, A.; Migeon, A.; Lebdi-Grissa, K. M. and Navajas, M. 2009. Geneticdiversity of the invasive tomato spider mite Tetranychus evansi (Acari: Tetranychidae) in the Mediterranean basin, assessed by sequences of the ribosomal internal transcribed spacers (ITS). IOBC/WPRS_ Bulletin. 49 :115-119.

Boubou, A., A. Migeon, G. K. Roderick and M. Navajas. 2011. Recent emergence and worldwide spread of the red tomato spider mite,

Tetranychus evansi: genetic variation and multiple cryptic invasions Biol. Invasions. 13:81-92.

De Moraes, G. J. and McMurtry, J. A. 1987. Effect of temperature and sperm supply on the reproductive potential of Tetranychus evansi (Acari: Tetranychidae). Exp. Appl. Acarol. 3: 95-107.

Gotoh, T.; Araki, R.; Boubou, A.; Migeon, A.; Ferragut, F. and Navajas, M. 2009. Evidence of co-specificity between Tetranychus evansi and

Tetranychus takafujii (Acari: Prostigmata, Tetranychidae): comments on taxonoùic and agricultural aspects. Int. J.of Acarol.35: 485- 501.

Gotoh, T.; Sugimoto, N.; Pallini, A.; Knapp, M.; Hernandez-Suarez, E.; Ferragut, F.; Ho, C. C.;
Migeon, A.; Navajas, M. and Nachman, G. 2010.

Reproductive performance of seven strains of the tomato red spider mite Tetranychus evansi (Acari: Tetranychidae) at five temperatures. Exp. Appl. Acarol. 52(3):239-259

Gutierrez, J. and Etienne, J. 1986. Les Tetranychidae de l'ile de la Reunion et qelquesuns de leurs predateurs. Agronomie Trop 41:8491

Ho, C.C., S.C. Wang and Y.L. Chien. 2005. Field observation on 2 newly recorded spider mites in Taiwan. Plant. Prot. Bull. 47:391-402

Migeon, A. 2005. Un nouvel acarien ravageur en France : Tetranychus evansi Baker et Pritchard : Cet envahisseur sans doute originaire d'Amérique du Sud s'attaque pricipalement aux Solanacées. Phytoma. 579: 38-43.

Migeon, A.; Ferragut, F.; Escodero-Colomar, L. A.; Fiaboe, K.; Knapp, M.; de Moraes, G. J.; Ueckermann, E. and Navajas M. 2009. Modelling the potential distribution of the invasive tomato red spider mite, Tetranychus evansi (Acari: Tetranychidae). Exp. Appl. Acarol. 48:199-212.

Moutia, L.A. 1958. Contribution to the study of some phytophagous Acarina and their predators in Mauritius. Bull. Entomol. Res. 49: 59-75.

Navajas, M.; de Moraes, G. J.; Auger, F. and Migeon, A. 2012. Review of the invasion of Tetranychus evansi: biology, colonization pathways, potential expansion and prospects for biological control. Exp. Appl. Acarol. 59(12):43-65.

Qureshi, A. H.; Oatmạn, E. R. and Fleschner, C. A.1969. Biology of the spider mite, Tetranychus evansi. Ann. Entomol. Soc. Amer. 62:898-903.

Roderick, G. K. and Navajas, M. 2003. Genes in new environments: Genetics and evolution in biological control. Nature Reviews Genetics 4: 889-899.

Silva, P. 1954. A new acari harmful to tomato in Bahia. Boletim do Instituto Biologica da Bahia, 1: 1-20. 